\title{
Explorative Learning of Wireless Network Security with Tele-Lab IT-Security
}

\author{
Dirk Cordel, Christoph Meinel, Stephan Repp, and Christian Willems \\ Hasso-Plattner-Insitut für Softwaresystemtechnik GmbH, Prof.-Dr.-Helmert-Straße 2-3, \\ 14482 Potsdam, Germany \\ \{dirk.cordel, meinel, stephan.repp, christian.willems\}@hpi.uni-potsdam.de
}

\begin{abstract}
Recently, IT-Security education and awareness creation have become important issues - especially for companies. Enterprises noticed that employees are often unknowingly responsible for security incidents. Due to the significant costs that may arise from such incidents, many companies nowadays spend a lot of money on awareness campaigns. Because today pupils are already able to use current computer technologies and the internet at a young age, the idea arose to start security education and awareness raising early in schools. This paper investigates the feasibility of a special security education program at the "Berufsbildenden Schule für Gewerbe und Technik" (a school providing vocational education) in Trier, Germany. Considering that security education needs to train students to deal with security problems in real environments, the Hasso-Plattner-Institut in Potsdam developed a special interactive web-based security training system. Besides theoretical knowledge, the so-called Tele-Lab system provides students with hands-on experiences by means of a virtual laboratory. This virtual lab is realized on the basis of virtual machines. Every user receives a dedicated virtualized computer to perform practical security exercises with real-life tools in a secure way. Using Tele-Lab, students of the "Berufsbildenden Schule für Gewerbe und Technik" were able to explore wireless network security issues autonomously. This paper subsequently describes the technical foundations of Tele-Lab, the students' hybrid learning process and the evaluation of the Tele-Lab training system.
\end{abstract}

Keywords: Explorative Learning, Computer Science Education, IT Security, Awareness Creation, Virtual Remote Laboratory

\section{Introduction}

Apprenticeship in Germany is based on a dual concept, the so-called Duale Ausbildung. This kind of education combines practical and theoretical components. While the theoretical part takes place in classes at specialized schools, the apprentice gains practical experience in a company. The apprenticeship usually focuses on certain aspects of a subject area. In computer science, software development, system administration or networking are possible domains. 
Due to the close cooperation between public educational institutions and companies, this successful system is considered to be worldwide one of the most exemplary. Nevertheless, some weaknesses of the dual concept have been reported in the past. Among these are high costs for enterprises, the lack of ability to teach many school graduates and the inadequate equipment in many schools - also in those with a technical orientation.

The last fact especially forces teaching personnel to focus on theoretical education. But particularly in the interest field of IT-Security, hands-on experience is indispensable but hard to provide - even with suitable hardware and software equipment. Tele-Lab IT-Security can help to overcome this problem.

Tele-Lab ${ }^{1}$ is a web-based training system for IT-Security which was developed at the Hasso-Plattner-Institut in Potsdam. The original objective of the system was to provide users not only with theoretical security knowledge but also practical experience in a realistic environment. Especially in the field of IT-Security it is important to gain practical experience to be able to secure computers, communications between computers or even whole networks. After the development of a first prototype of the Tele-Lab system and first user feedback, it turned out that the architecture is also appropriate to increase the awareness of users regarding security issues.

Companies often spend a lot of money on security training for their employees. The reason for this is the high number of failures of computer systems, security leaks or attacks on computer systems caused by human factors. Employees or computer users in general often do not comply with instructions, because they are not aware of the potential consequences. The idea of Tele-Lab is to give users the chance to perform realistic security exercises and experience the consequences themselves which tends to result in increased security awareness. In a company, for example, an executive manager can tell his employees to use strong passwords for authentication but strong passwords are hard to remember and inconvenient. In Tele-Lab the users are able to crack passwords and find out how easy it is to reveal passwords that do not satisfy general security guidelines. In consequence of such hands-on experience, it is expected that the users will be willing to choose stronger passwords in future. Awareness has become an important topic as nearly every person nowadays owns a computer and has an internet connection. Even for pupils at a young age it is normal to make use of current computer technologies. Thus, the idea arose to start awareness training in schools. A computer tool cannot explain better than a human teacher could, but it can present information in a clearer, maybe a better way than a teacher could. Currently, students tend to be more visual learners than in previous generations because their world is rich in visual stimuli [1-3].

This paper describes the application of Tele-Lab in a German school in a hybrid course. Besides providing knowledge and hands-on experience on a security topic relevant to the students, the special kind of explorative learning (described in chapter 4) intends to increase the motivation of learning and the extent of awareness regarding security issues. Furthermore the learning activities have been moved online and time traditionally spent in the classroom is reduced.

1 see http://Www.hpi-web.de/meinel/projects/tele-lab_it-security.html and http://www. tele-lab.org 


\section{Tele-Lab Architecture}

When performing practical security exercises on a computer, special requirements arise. Users usually need privileged rights to execute special programs or must have access to certain computer resources like configuration files. If such rights are granted to users, it's very likely that, after a while, the computer system will be damaged due to faulty operation and has to be recovered. Furthermore, the privileged rights could be misused, e.g. to attack other computers in the network. Tele-Lab therefore uses virtual machines as a kind of virtual laboratory.

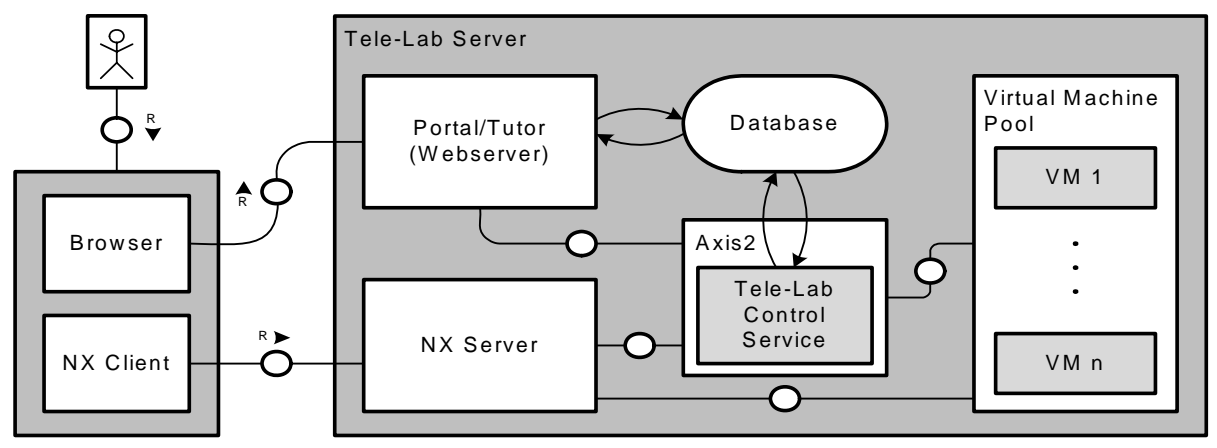

Fig. 1. Tele-Lab architecture (FMC notation)

They are integrated in the online training system to provide the users with handson security experience in a secure and efficient way. Figure 1 illustrates the architecture of Tele-Lab. The Tele-Lab Server consists of the following main components:

- Portal/Tutor (Web server): A web server provides the portal of the Tele-Lab training system and presents the different security chapters to the users. On this portal a user can log into the system and take part in the training course. The web server with its dynamic WebPages can also be seen as a tutor that offers users the learning material especially didactically.

- Database/Repository: A database is used to store several types of information. Besides general information about the users like name, credentials, group, etc. it contains individual information about the user's learning progress. Thus a user is able to continue his training at a later date without repeating already completed exercises. Furthermore, information about the virtual machines is stored in the database which is used to control their management. Finally, the structure of the learning units is stored here.

- Virtual Machine Pool: The virtual machine pool is a collection of prepared virtual machines that build the virtual laboratory for the users. Instead of using real computers, several virtual machines are operated on one powerful physical computer. Those virtual machines already contain all needed security applications for the exercises. This saves hardware resources, eases the management of the 
system and increases the overall security. Due to the isolated operation mode of a virtual machine it can be easily recovered in case of failure without affecting other running virtual machines or the host computer. For this reason it is even possible to grant users privileged rights on the virtual machines. Currently VMware Server ${ }^{2}$ is used in the Tele-Lab system as virtual machine monitor (VMM), i.e. as technology to build and operate the virtual machines.

- Tele-Lab Control Server: The control server is responsible for managing the state of the virtual machines and to guarantee an efficient interaction between the user and his dedicated virtual machine. For this reason the control server, for example, handles the assignment of users to virtual machines, the automatic recovering of failed virtual machines, etc.

- NX Server ${ }^{3}$ : In order to provide the users a remote graphical interface to the virtual machines, the NX Server technology is used in the Tele-Lab system. Besides saving bandwidth for communication, this technology has the advantage that all traffic is encrypted and user session management is supported.

\section{Tele-Lab Learning Units}

Tele-Lab mainly offers learning units on cryptography and network security. However, due to the flexible architecture of Tele-Lab it is possible to integrate additional chapters e.g. for other user groups with different background or interests [4]. Subsequent, the general structure of learning units will be illustrated by explaining the wireless network security chapter more in detail. This chapter was also chosen to train the participants of the grade of school. Since nowadays wireless networks are very popular but often still not secured by encryption, the chapter seemed to be interesting for the students and also appropriate to increase their awareness.

Before starting the security training a user has to access the Tele-Lab portal (http://www.tele-lab.org) and log-in. For this purpose all scholars in the computer science course were registered to the system with a unique user account in advance. After login an overview of available security units/chapters is displayed. Besides a chapter on authentication and port scanning the "Wireless Network Security" unit is selectable for standard users at the moment. Further units on e.g. firewalls, intrusion detection, e-mail security, etc. are already integrated in Tele-Lab, but not yet open to the public.

Figure 2 shows the user interface of the Tele-Lab training environment: the tutoring system within the browser window and the virtual machine for exercising. In general every chapter is divided into three different parts, each marked with a symbolic icon in the tutor's chapter overview. In the Tele-Lab learning unit on e.g. "Wireless Network Security", those parts consist of the following kinds of information and challenges:

\footnotetext{
2 see http: //WWW. vmware.com/products/server

${ }^{3} \mathrm{NX}$ is a remote desktop access protocol that allows secure access to Windows RDP-, VNC- and X11-Servers (see ht tp : //WWW . nomachine . com)
} 
- Introduction: This part provides the users with relevant background knowledge on the respective topic. In the "Wireless Network Security" chapter the user gets familiarized with different WiFi technologies like Wireless LAN or Bluetooth. Furthermore, the functionality of mechanisms and protocols is explained and related security weaknesses are described [5].

- Tools: In this section important hacker tools and security-relevant applications for Windows and Linux are presented. "Kismet" or the "Aircrack Suite" are examples for relevant tools that are described in the "Wireless Network Security" unit. Thus, the user learns to operate these tools to use them in the exercises later on.

- Exercises: Especially this section makes Tele-Lab a unique training system for ITSecurity. Users can gain practical knowledge by performing exercises with realworld tools on their dedicated virtual machines. For each exercise which requires a realistic computer environment, the user can request a virtual machine by simply pressing the appropriate button displayed on the webpage. A remote desktop connection will be established to the user's virtual machine. The participant of the Tele-Lab training system needs nothing more than a standard browser with java support for being able to control the virtual machine's desktop via the NX-applet. In the "Wireless Network Security" chapter e.g. the user can crack the key of a WEP-encrypted WLAN communication on the virtual machine and directly see the weaknesses of WEP-encryption. It is expected that after such an experience and additional recommendations provided in the Tele-Lab system the participant will have the needed knowledge and awareness to operate a wireless network in a secure way.

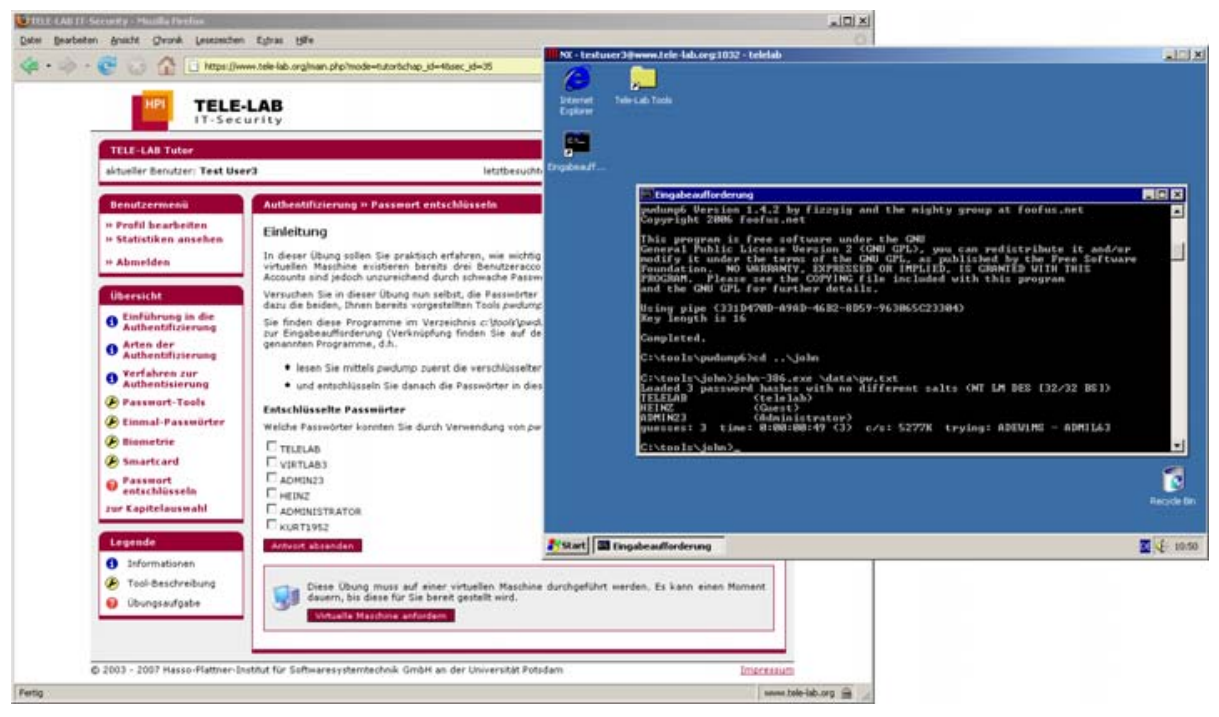

Fig. 2. Tele-Lab training environment (Tutor and Virtual Machine) [6] 


\section{$4 \quad$ Lecture Style}

Traditional pedagogy distinguishes between different learning styles. These distinct learning styles are closely related and take into consideration different personality types. Many learning style models have been developed and used over the years. Some of the most widely used pedagogy theories which take into consideration the different personality types mentioned have been proposed by Carl Jung, Myer Briggs, Kolb, and Howard Gardner [7]. The commonly used Visual / Auditory / Kinesthetic Learning Style Model classifies people into three main categories [8].

Visual Learners: these people learn through seeing. They prefer to think in terms of pictures, and learn best from visual aids such as: diagrams, videos and printed handouts. Auditory Learners: these people learn through listening. They like listening to lectures engaging in discussions and talking things through. For them, nuances of audio such as tone and speed have a profound effect on their level of understanding. Kinesthetic Learners: these people learn by touching or building physical models and are therefore also called Tactile Learners. Some of them may find it hard to sit still in lectures as they want to experience things physically, and can not just listen to the descriptions or read about them [9]. But an individual commonly possesses different learning styles.

Therefore, our educational concept is based on the assumption that acquiring knowledge takes place in an active and knowledge-enriching process which is initiated by the learner himself.

Teaching in the sense of knowledge transfer is not just a uni-directional process. Knowledge is gained in relation to the specific individual background and experiences of the student. People do not perceive the world as it exists (objective), but the way it appears to them. Learning is a self-referred, subjective and the cognitive process of development is made up of the reinterpretation of already known facts. Though this learning process can be triggered by external impulses, it is determined by the already existing and developed individual structures of the learner [10-12]. The Tele-Lab learning units described in the paper at hand obey the principle of constructivism [13] which can be characterized as follows:

- Learning happens through active participation of all learners. They must be motivated and interested in what they do and how the objective can be realized.

- The learners control and guide their own learning-process. The intensity of this self guidance may vary depending on the learning situation.

- Learning is practiced constructively. The individual experience and knowledge background is taken into consideration. Subjective interpretations take place.

- Learning takes place in a specific context.

- Learning is socially orientated by being interactive and taking into consideration the socio-cultural background.

These characteristics imply a teacher's role where having a very good grasp of the knowledge is nothing but a basic qualification. The teacher is the one to passively offer the knowledge instead of actively transferring it. Instead of being a pure instructor, the teacher will be creator of a learning environment and must also care of 
progress management besides promoting, moderating and attending to the selfcontrolled learning [14, 15, 12].

Koubek [16] describes two meta-levels when developing competences in the education of information scientists: the level of technology and the level of discourse analysis. The first level expresses the importance of providing knowledge on concrete areas of technology (i.e. IT Security) and should be the main focus. The discourse level defines the scope of activity concerning the above technologies. Moreover, [17] gives ideas on a competence model for computer scientists. Brinda specifies that the learners' perspective should be transformed to the state of mind of a computer science expert during the education process. The student performs a role alternation and becomes an IT specialist. The objective is to enable him or her to learn completely autonomously after finishing the formal education. An example of such a learning style is described in [18].

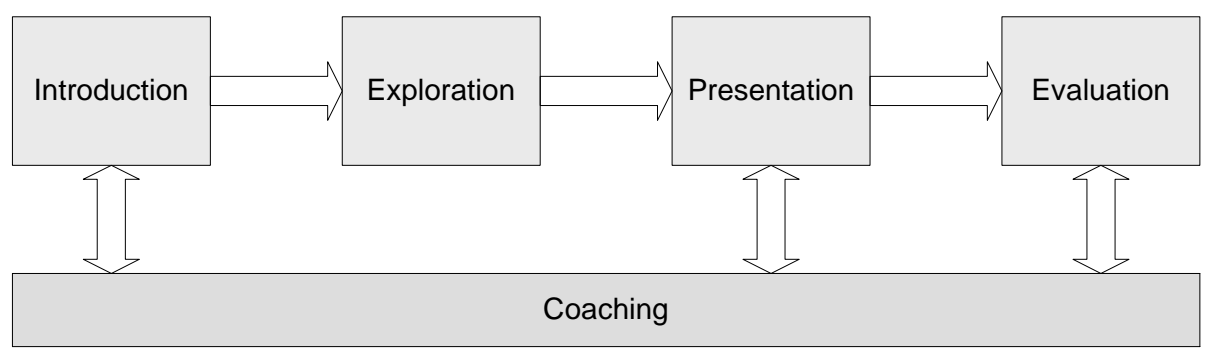

Fig. 3. Lecture style overview

Based on this theoretical foundation, the lesson concept is introduced as follows:

- Introduction (20 min): For motivation, the lecturer presents sensational headlines from newspaper articles on WLAN security problems, such as: " $30 \%$ of all wireless LANs unprotected", "Secure enterprise WLAN needs complex infrastructure" etc. These headlines are used to trigger a general discussion on wireless security. The discourse should introduce the students to security problems at home or in enterprises. Students are assigned the task of developing a secure concept for a wireless network in the exploration phase. Finally, they are asked to prepare a presentation of their results.

- Exploration (120 min): Using the Tele-Lab system, the students explore autonomously the theoretical and practical matters of wireless security in groups of two. In addition to Tele-Lab, the learners are allowed to use other different information sources such as the tele-TASK ${ }^{4}$ archive, the Internet in general or textbooks. The important aspects of the exploration phase are the independent work of the students and the self controlled learning guided by the Tele-Lab system. At the end of this phase the students have to work out their presentation.

${ }^{4}$ tele-TASK is a state-of-the-art e-Lecturing toolkit; its archive provides publicly recorded lecture series on different topics (see http://WWW.tele-task.de) 
- Presentation (90 $\mathrm{min})$ : All groups introduce their results to other students in a presentation of 10 minutes. Afterwards, they discuss the solutions to reflect and analyze their work. Open issues and questions will also be answered during the discourse.

- Evaluation (90 min): The students have a written exam on the theoretical background and the practical applications. They also give an evaluation of the Tele-Lab system and the constructive learning concept.

- Coaching: The function of the teacher in our concept is to act as a kind of coach instead of being a lecturer. The teacher must introduce topics and objectives, and motivate the students. If problems arise, the coach gives help and hints for solutions.

\section{Evaluation}

Based on this explorative concept a few other projects have already been performed at the school but without using the Tele-Lab system. The projects usually take place in the third year of studies to ensure certain basic competences of the students in teamwork. It's worth mentioning that due to the type of school, the students usually have heterogeneous graduations.

In order to get feedback after the learning phase, the eleven students were asked about their personal opinion on the Tele-Lab system. For this reason, they had to fill out a questionnaire comprising 21 questions. The questions covered various aspects concerning usability, interestingness, satisfaction and information content. In this paper only four questions were chosen for a more detailed discussion.

The first question was about the all-over satisfaction with the Tele-Lab system. Figure 4 shows the general contentment of the users with 18.2 percent "satisfied" and 81.8 percent "rather satisfied". None of the students said they were rather dissatisfied or even dissatisfied.

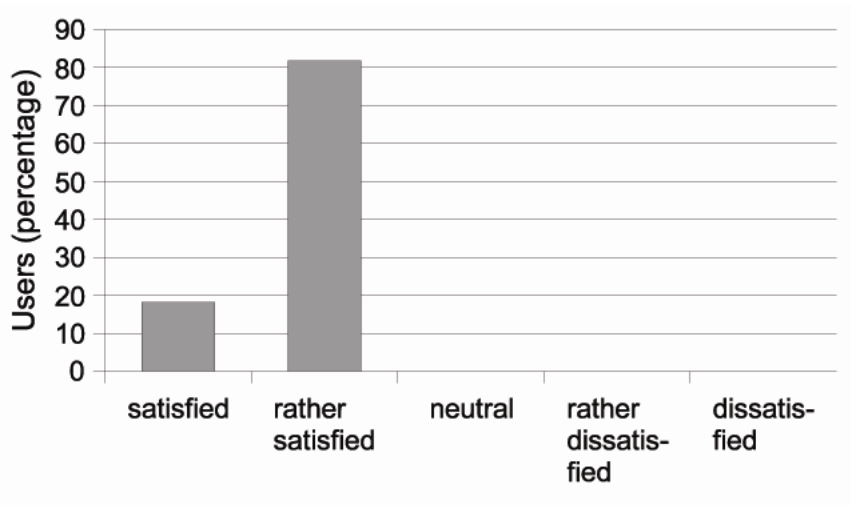

Level of Satisfaction

Fig. 4. Overall satisfaction with Tele-Lab 
One part of the questionnaire covered the usability of the system. Among certain questions about the structure or navigation of the system there was one question about the first-time ease of use of Tele-Lab. Figure 5 illustrates that it wasn't difficult for the participants to use the system for the first time.

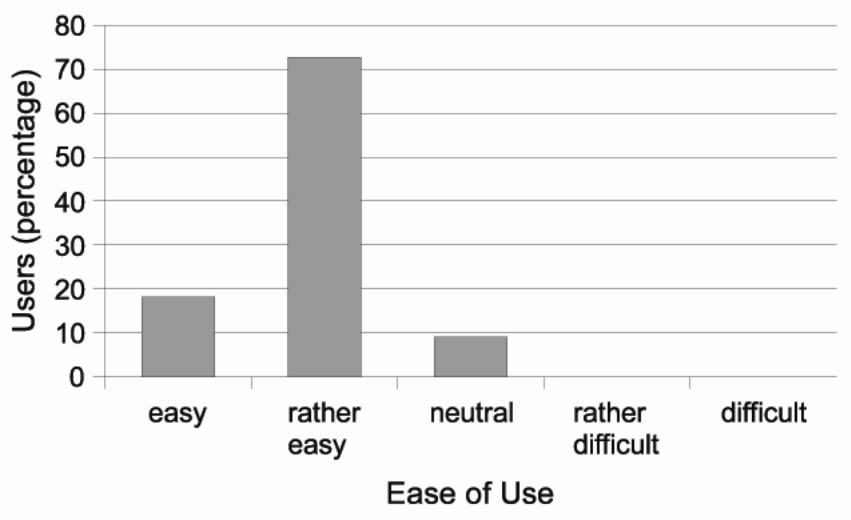

Fig. 5. First time ease of use

Figure 6 shows the result of the students' opinions regarding the usefulness of the practical exercises (one student didn't mark this field). Since this is a special feature of Tele-Lab which also distinguishes the system from traditional learning systems, this question was one of the most important ones for the Tele-Lab project team. For the majority of students $(70 \%)$ the practical exercises were useful or rather useful. However, 20 percent of the users evaluated the exercises as rather useless.

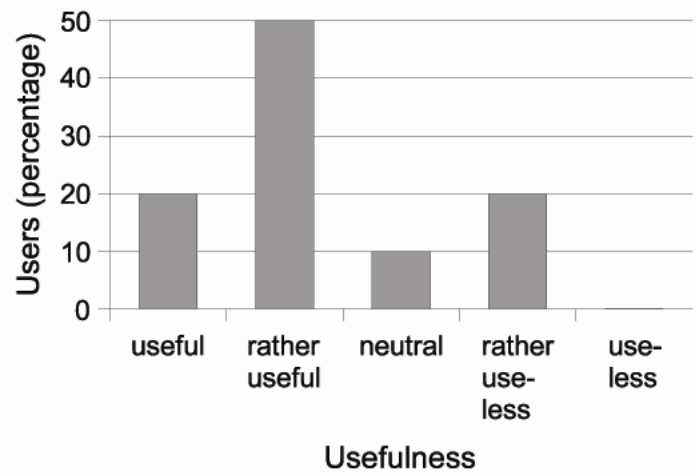

Fig. 6. Usefulness of practical exercises 
Besides the presentation of the training system, the learning content has to attract the users. For this reason one question asked about the interestingness of the system. The result of the answers was positive as well (see figure 7).

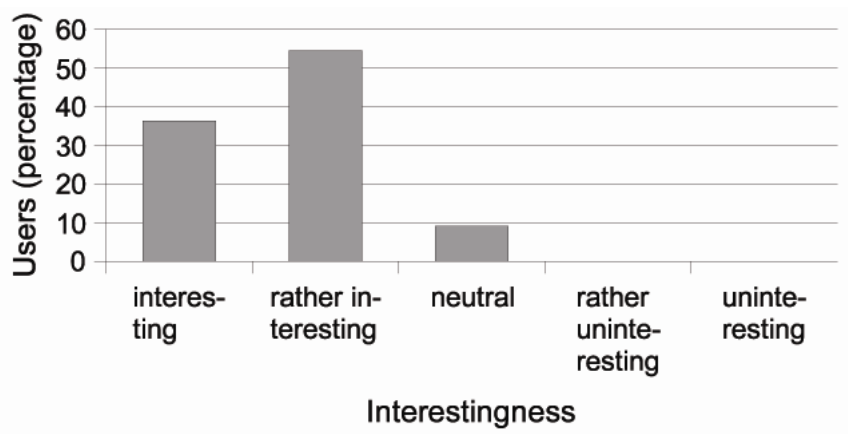

Fig. 7. Overall interestingness of Tele-Lab

In order to investigate and prove the positive evaluation of the system, the log files of the system were additionally analyzed. During the two hour exploration phase of the eleven students, a total number of 292 website hits was counted within the TeleLab. Although there were two other chapters accessible to the students, they focused on their task to deal with the "Wireless Network Security" chapter. Only 2.05 percent of website hits were performed in the "Authentication" and "Port scanning" chapter.

After the learning time in school, the students' accounts were not deactivated. It's worth mentioning that further investigations of the log files revealed a 110.27 percent increase of website hits by the students at a later time. 6 students freely accessed the Tele-Lab system again in their spare time and performed 322 website hits. With about 75 percent, most of the clicks were still counted in the "Wireless Network Security" chapter but this time the students also spent more time viewing the other chapters. Thus, the analysis shows that at least 54.5percent of the students were really interested in the Tele-Lab system and the students learn in a self-directed way.

At the end of the learning course, the students had to write an exam. This exam was intended to test their knowledge on wireless network security which they gained by means of the Tele-Lab system. The result of the test was an overall average grade of 2.0 (B Mark in England). The overall average grade of previous exams was approximately 2.3. It seems to be a small enhancement in the students' results but this has to be analyzed in more detail in future.

\section{Conclusion and Outlook}

This paper describes the application of the Tele-Lab system at a German school to train students in wireless network security. Besides the goal of providing students with practical hands-on security experiences, the project aimed to enhance the students’ learning motivation and security awareness. 
Our hybrid course-style with Tele-Lab can be used in different situations. In our blended learning approach, we used it to introduce a new subject in an autonomous and explorative way. It can also be used for distance learning, where a student (or a professional) can learn at home. Another interesting aspect is for collaborative learning. The Students worked in a group and collect information, which they share and discuss.

As described in the evaluation part, the first experiences with Tele-Lab in schools are promising. The evaluation shows that the majority of users are satisfied with the system. The students' feedback regarding the interestingness of the contents and the usability of the training system was highly positive too. A detailed analysis of the system's log files revealed that at least $54.5 \%$ of the students were really interested in Tele-Lab. They freely accessed the system in their spare-time and performed more website hits than during their regular class. This hybrid learning is to combine the two learning environments to maximize students learning. Although for most of the students the integrated exercises were rather useful, the result is improvable.

Due to the limited number of students who used and evaluated the system there are deeper investigations necessary to confirm this evaluation. For this reason further school projects are planned which will integrate Tele-Lab in their classes too. For the upcoming projects other existing chapters of Tele-Lab on network security or cryptography will be chosen for a security training course. Thus, it is also possible to determine which topics are most appropriate for security education in schools.

\section{References}

1. Owston, R. D.: The world wide web: A technology to enhance teaching and learning?, Educational Researcher, Volume 26. (march 1997) 27-33

2. Linckels, S., Repp, S., Karam, N., Meinel, C.: The virtual tele-TASK professor: semantic search in recorded lectures. In Russell, I., Haller, S.M., Dougherty, J.D., Rodger, S.H., eds.: Proceedings of the 38th SIGCSE Technical Symposium on Computer Science Education, SIGCSE 2007, Covington, Kentucky, USA, March 7-11, 2007, ACM (2007) 50-54

3. Linckels, S., Dording, C., Meinel, C.: Better results in mathematics lessons with a virtual personal teacher. In Nagorski, A., Brouilette, G., Rhodes, C., eds.: Proceedings of the 34th Annual ACM SIGUCCS Conference on User Services 2006, Edmonton, Alberta, Canada, November 5-8, 2006, ACM (2006) 201-209

4. Hu, J., Cordel, D., Meinel, C.: New media for teaching applied cryptography and network security. In: EC-TEL First European Conference on Technology Enhanced Learning. (2006) 488-493

5. Willems, C.: Tele-Lab IT-Security: An architecture for practical IT security education on the web. In Proceedings of the 2nd International Workshop on eLearning and Virtual and Remote Laboratories (2008)

6. Willems, C.: Eine erweiterte Architektur für den Tele-Lab Server: Implementierung eines generischen Interfaces für Virtual Machine Monitors. Master's thesis, Universität Trier (2006) 
7. Schroeder, C.: New students - new learning styles.

http://www.virtualschool.edu/mon/Academia/KierseyLearningStyles.html, Accessed October 2007.

8. Bogod, L.: Learning styles. http://www.ldpride.net/learningstyles.MI.htm Accessed December 2007.

9. Sharda, N.K.: Authoring educational multimedia content using learning styles and story telling principles. In Friedland, G., Hürst, W., Knipping, L., Mühlhäuser, M., eds.: Proceedings of the International Workshop on Educational Multimedia and Multimedia Education 2007, Augsburg, Bavaria, Germany, September 28, 2007, ACM (2007) 93-102

10. Arnold, R., Schüssler, I.: Wandel der Lernkultur. Wissenschaftliche Buchgesellschaft, Darmstadt (1998)

11. Bonz, B.: Wandel der Lernkultur. Schneider Verlag GmbH, Hohengehren (2003)

12. Siebert, H.: Pädagogischer Konstruktivismus. Luchterhand, München (2003)

13. Schelten, A.: Pädagogischer Konstruktivismus. Franz Steiner Verlag, Stuttgart (2000)

14. Gudjons, H.: Krisen als Wandlung im Lehrerberuf. Pädagogik 11 (2002) 6-12

15. Frey, K.H.: Selbstorganisiertes Lernen in (berufs-) biographischer Reflexion. Julius Klinkhardt Verlag, Bad Heilbrunn (1998)

16. Koubek, J.: Informatische Allgemeinbildung. In Friedrich, S., ed.: Unterrichtskonzepte für informatische Bildung, INFOS 2005, 11. GI-Fachtagung Informatik und Schule, 28.-30. September 2005 an der TU Dresden,. Volume 60 of LNI., GI (2005) 57-66

17. Brinda, T., Schulte, C.: Beiträge der Objektorientierung $\mathrm{zu}$ einem Kompetenzmodell des informatischen Modellierens. In Friedrich, S., ed.: Unterrichtskonzepte für informatische Bildung, INFOS 2005, 11. GI-Fachtagung Informatik und Schule, 28.-30. September 2005 an der TU Dresden. Volume 60 of LNI., GI (2005) 137-148

18. Repp, S., Ziegler, R., Meinel, C.: Lernortkooperation in der IT-Ausbildung Kompetenzentwicklung in Projekten. In Schubert, S., ed.: Didaktik der Informatik in Theorie und Praxis, INFOS 2007, 12. GI-Fachtagung Informatik und Schule, 28.-30. September 2007 in Siegen. Volume 112 of LNI., GI (2007) 135-14 